\title{
CONTRATO SOCIAL E DIREITO NATURAL EM JEAN-JACQUES ROUSSEAU
}

\author{
Lucas Mello Carvalho Ribeiro* \\ lucasmcr@yahoo.com.br
}

RESUMO É certamente hegemônica na recepção do pensamento político rousseauniano, de seus primeiros momentos à exegese contemporânea, a tese segundo a qual o contrato social seria incompativel com a negação do direito natural. A convicção comum a esses intérpretes, herdada da tradição jusnaturalista moderna, é a de que, na ausência de uma obrigação moral prévia - a lei natural - e, portanto, de uma sanção que confira força vinculante à promessa daqueles que se engajam no ato de contratar, o pacto fundamental não passaria de um formulário vão, cujos termos seus celebrantes dificilmente cumpririam. As teorias contratualistas da origem do corpo político encontrarse-iam, assim, necessariamente atreladas ao jusnaturalismo. Na contramão desse viés de leitura, pretendemos neste artigo desenvolver e sustentar a hipótese de que o contrato social concebido por Jean-Jacques Rousseau, distinto da forma contratual clássica em aspectos cruciais, dispensa a sanção da lei de natureza. Será o caso, para tanto, de esmiuçar a estrutura sui generis do pacto rousseauniano, revelando, finalmente, de onde emana seu poder coercitivo.

Palavras-chave J.-J. Rousseau, Contrato social, Direito natural, Sanção.

ABSTRACT The conception according to which the social contract would not be compatible with the refusal of natural right is widely hegemonic in the reception of the Rousseaunian political thought, from its beginnings to the present day exegesis. The common contention of these interpreters, inherited

* UFMG. Artigo recebido em 25/05/2016 e aprovado em 05/10/2016.

KRITERION, Belo Horizonte, nº 136, Abr./2017, p. 125-138 
from the modern jusnaturalistic tradition, is that, in the absence of a previous moral obligation - the natural law - and therefore of a sanction able to procure binding force to the promise of those who engage in the act of contracting, the fundamental pact would be but a vain form, whose terms its celebrants would hardly keep. Thusly, the contratualist theories of the origin of the political body would necessarily find themselves linked to jusnaturalism. As a counterpoint to this interpretative bias, we intend in the present article to develop and sustain the hypothesis that the social contract conceived by Jean-Jacques Rousseau, distinct from the classical contractual form in some crucial aspects, dismisses the sanction from the law of nature. To that end, it will be relevant to unravel the sui generis structure of the Rousseaunian pact, elucidating, lastly, the source of its coercive power.

Keywords J.-J. Rousseau, Social contract, Natural right, Sanction.

\section{Contrato social e direito natural: delimitação do problema}

É bem conhecida a discordância entre os intérpretes de Jean-Jacques Rousseau no que diz respeito à sua posição em face do jusnaturalismo. De um lado, aqueles que sustentam, na esteira da exegese pioneira de Vaughan (1915, pp. 28-29), que o genebrino rejeita decisivamente a ideia de direito natural. De outro, apoiados principalmente em Derathé (2009, pp. 229-258) - que, por sua vez, deve muito ao trabalho de Haymann (1945, pp. 65-110) -, aqueles segundo os quais ele preserva em seu pensamento político um lugar de destaque para a lei de natureza. Posto não ser o escopo deste artigo uma análise do estatuto do direito natural em Rousseau (mas, antes, o desvelamento da estrutura do contrato social por ele proposto e suas implicações no que concerne à sua sanção), interessam-nos menos os fundamentos e meandros dessa dissensão ${ }^{1}$ do que o fato de que ela se desdobra a partir de uma convergência inicial, a saber, a ideia de que haveria, necessariamente, uma implicação mútua entre jusnaturalismo e contratualismo.

Com efeito, tanto Vaughan (1915, p. 292) quanto Derathé (2009, p. 241) acreditam que, sem o amparo da lei de natureza, o contrato social não passaria de um formulário vão. O argumento subjacente a essa postulação é simples. É preciso dar peso à promessa de obediência às disposições contratuais. Faz-se

1 No que concerne à relação entre Rousseau e a tradição jusnaturalista moderna, seguimos, em sua quase totalidade, a argumentação avançada por Vargas (2008, pp. 25-52) em "Rousseau et le droit naturel". 
imperativo, portanto, que exista alguma instância coercitiva para garantir que os contratantes cumpram a palavra empenhada no ato mesmo de contratar. Como o Estado e seus dispositivos de coação (legislação positiva, força pública etc.) são instaurados justamente pelo contrato ao qual trata-se de conferir sanção, alguma forma de obrigação anterior a ele impõe-se como necessária. A lei natural - regra de justiça imutável, inerente à natureza racional do ser humano, ${ }^{2}$ com a qual todo homem estaria moralmente obrigado a se conformar em suas relações com seus semelhantes (cf. Derathé, 2009, p. 230) - funcionaria exatamente como essa "lei antes das leis" (Vargas, 2008, p. 26), como essa norma prévia que revestiria o pacto social de força vinculante, não bastando para tanto o livre consentimento ao ato de contratar e às condições por ele impostas. Assim, mesmo na ausência de pertencimento a uma comunidade política e de sujeição a um corpo de leis convencionadas, os homens ver-se-iam submetidos a um parâmetro normativo. Diante do exposto, não restaria senão concluir pela incompatibilidade entre teorias contratualistas da origem do corpo político e a negação do direito natural. Tese enunciada enfaticamente, entre outros, por Jean-Pierre Marcos: "Sem nenhuma dúvida [sic], a falta da lei natural traduzse, em uma perspectiva contratualista, na ausência de toda obrigatoriedade principial, quer dizer, de toda a obrigação que funda [...] o contrato promotor de todas as obrigações" (1995, p. 167).

Como indicamos, boa parte dos rousseauístas que se debruçaram sobre o tema abraça essa linha de raciocínio. Haymann por exemplo, em diálogo com a introdução de Maurice Halbwachs ao "Contrato social" (a ser oportunamente mobilizada), é claro ao afirmar que "o contrato social, como todo outro, precisa da sanção de uma regra segura (moral ou de direito) que the dê força coercitiva para o presente e para o futuro, uma instância inquebrantável que ligue os contratantes às suas promessas" (1945, p. 70). No que ele é seguido de perto por Derathé:

Um pacto só tem sentido se aqueles que o concluem sentem-se ligados pelo engajamento que assumem. Isso não supõe apenas que eles não sejam coagidos a dar seu consentimento, mas também que respeitem a palavra dada. Assim, a obrigação de respeitar o pacto só tem seu fundamento na lei natural e no dever de cumprir seus compromissos. Se suprimirmos a lei natural, o contrato social, privado de toda sanção moral, não tem mais qualquer garantia além da força. Ele só pode ser uma formalidade desprovida de sentido para homens que ignoram que se deve cumprir a palavra. Seria derrisório pretender fundar toda sociedade humana sobre convenções se os homens não tivessem nenhuma ideia dos engajamentos mútuos e da obrigação de respeitá-los. Rousseau

2 Sobre a lei natural como preceito da razão, remete-se, a título de ilustração, a Hobbes (1651, Parte I, Cap. XIV, p. 80); e Pufendorf (1734, Liv. II, Cap. III, § XIII, p. 217). 
não poderia rejeitar a ideia de lei natural sem, no mesmo golpe, privar o contrato de toda sanção. [...] a teoria do contrato social não é compatível com a negação da ideia de lei natural, já que esta serve de fundamento às convenções de onde nascem as diversas sociedades (2009, pp. 240-242, grifos nossos).

Mesmo Vaughan (1915, p. 291) evoca a indissociabilidade entre pacto social e lei natural como motivo da supressão do segundo capítulo do "Manuscrito de Genebra" - no qual, a partir de uma refutação do verbete enciclopédico "Droit naturel", de Diderot, o genebrino tece uma argumentação contundente contra os principais preceitos do jusnaturalismo - da versão definitiva do "Contrato". Vaughan compreende essa omissão como resultado da escolha feita por Rousseau em resposta ao dilema que se lhe apresentava, qual seja: ou manter sua crítica radical à tradição jusnaturalista e descartar o contrato social como fonte do estado civil, ou conservá-lo como fundamento do corpo político e ignorar a démarche que desembocou na rejeição da ideia de lei natural (sob pena de o pacto revelar-se inócuo). Porque não dispunha de nenhuma outra base além do contrato sobre a qual repousar o Estado, Rousseau, ainda segundo Vaughan, teria optado por sacrificar "uma das mais convincentes argumentações já escritas" (1915, p. 291), a saber, o excerto no qual ele havia exposto a referida réplica de "Droit naturel":

É difícil resistir à suspeição de que Rousseau suprimiu o herético capítulo não porque ele era irrelevante, mas porque ele era fatalmente relevante [...]; porque ele tornouse ciente de que, refutando a ideia de lei natural, ele havia inadvertidamente ferido de morte a força vinculante do contrato; e porque, não tendo outro princípio para colocar no lugar do contrato como fundação da sociedade civil, ele viu-se compelido a passar em silêncio as baterias que ele havia inadvertidamente desmascarado contra si próprio. Em poucas palavras, viu-se compelido a remover a refutação e manter o contrato social de pé (Vaughan, 1915, p. 292, grifos nossos). ${ }^{3}$

Vaughan acaba por antecipar, destarte, a objeção que Hochart lhe endereçaria décadas mais tarde, segundo a qual, se Rousseau tivesse efetivamente rechaçado o direito natural, "ele jamais poderia ter escrito o Contrato social" (1967, p. 72).

3 Vale notar que Vaughan (1915, p. 292) deplora abertamente a saída tomada por Rousseau, que, no seu entender, o reconcilia com a tradição (jusnaturalista/contratualista), subtraindo de seu pensamento, de uma só vez, coerência e originalidade. Ele chega a dizer que o contrato social seria um "elemento perturbador" (1915, p. 44) na teoria jurídico-política do genebrino, e lamenta que ele não tenha dado consequência à ideia de que o discernimento de um "interesse comum" poderia bastar como suporte fundacional para a instauração do político (1915, p. 44). Nesse aspecto (entre outros), discordamos do comentador inglês, cuja interpretação, no nosso entendimento, toma excessiva liberdade em relação ao texto rousseauniano, que não permite vislumbrar o contrato como matéria estranha ao restante da doutrina (tanto que ele é trazido à baila e conceitualizado mesmo na versão inicial do "Contrato social", que contempla a recusa da lei de natureza), tampouco asseverar que a percepção de um interesse comum (ou de uma vontade geral) dispensa a celebração de um pacto por parte daqueles que irão formar o corpo político a ser instituído. Na verdade, a identificação desse interesse é, como se vê bem no início do segundo livro do texto definitivo da obra ora em questão, condição de possibilidade para a realização do contrato. 
Nesse ponto, cumpre ressaltar, os comentadores em tela não fazem mais do que repercutir um princípio basilar do jusnaturalismo moderno, formulado de diferentes maneiras por suas figuras centrais. Hobbes articula-o com todas as letras: "Daquela lei de natureza pela qual somos obrigados a transferir a outrem direitos tais que, sendo retidos, impedem a paz da humanidade, segue-se [...] que os homens cumpram os pactos celebrados; sem o que os pactos são em vão e senão palavras vazias" (1651, Parte I, Cap. XV, p. 88, nós grifamos). ${ }^{4}$ No mesmo espírito, Pufendorf diz que, "para contratar qualquer obrigação por promessa ou convenção, é preciso [...] que haja um poder moral [no caso do contrato originário, fundante da soberania, trata-se, bem entendido, da lei natural] para garantir o cumprimento daquilo que se acordou" (1734, Liv. III, Cap. VII, § VI, p. 469). E não é por outra razão senão a necessidade de sancionar o contrato social que Grotius elenca o cumprimento de promessas como artigo de direito natural: "Não há nada mais conforme à boa fé que deve reinar entre os homens do que cumprir aquilo a que nos engajamos para com os outros" (1746, Liv. II., Cap. XI. § I, p. 234).

Isso posto, nosso propósito doravante será mostrar que essa inextricabilidade entre lei natural e pacto social, cláusula inconteste do jusnaturalismo moderno amplamente aceita entre rousseauístas, ${ }^{5}$ não pode ser adequadamente aplicada ao contratualismo de Rousseau. Dito de outro modo, pretendemos demonstrar que a arquitetônica sui generis do contrato social por ele proposto, certamente distinta da forma contratual clássica, dispensa a sanção prévia da lei de natureza, desatando o nó que tradicionalmente os vinculava.

\section{Lei natural e sanção segundo Rousseau}

Temos um primeiro (e forte) indício de que o contrato social rousseauniano não poderia depender da força vinculante da lei natural no fato de que o filósofo genebrino põe em xeque, no "Manuscrito de Genebra", a própria eficácia impositiva de uma tal lei. Com efeito, após questionar o caráter racional da lei de natureza (trata-se, lembremos, de um preceito da razão), Rousseau (1964a, pp. 284-286) aprofunda sua crítica a esse construto expondo que, mesmo se o homem dispusesse - já no estado de natureza - de sua capacidade meditativa e que ela se sobrepusesse às suas paixões egoístas, ele não observaria as injunções da lei

4 No De cive, o filósofo de Malmesbury (cf. 2002, Parte I, Cap. III, §I, p. 53) pronuncia-se de maneira quase idêntica.

5 Marcos (erroneamente, diga-se) chega a reivindicar tratar-se de uma unanimidade: "É interessante observar que os comentadores de Rousseau concordam em reconhecer que a rejeição [...] da lei natural e de sua força coercitiva tem por consequência privar o contrato social de toda sanção moral [...]" (1995, p. 169). 
natural precisamente por estas carecerem de sanção. Em poucas palavras, ainda que o direito natural-racional pudesse ser discernido pelos homens (concessão de Rousseau ao argumento jusnaturalista), ele não seria aplicado (cf. Spector, 2012, p. 144).

Eis como nosso filósofo justifica esse juízo. É de se esperar que a lei natural seja eficaz já no estado de natureza, isto é, em um estado de independência no qual os homens não podem ainda contar com a regulação estatal. Mas como assegurar a obediência a determinados preceitos (racionais) na falta de uma autoridade comum capaz de distribuir penas àqueles que os infringirem? Qual seria o fundamento de obrigação da lei em um tal cenário? Em suma, o que conferiria sanção à lei de natureza na ausência da "espada pública"?

Sob a ótica rousseauniana, a ausência de garantias de reciprocidade, ou seja, as dúvidas sobre seu cumprimento generalizado ofuscam os possíveis benefícios da obediência à lei de natureza: "cada um segue seu estrito interesse enquanto não tem a certeza de que os outros não farão o mesmo" (Spector, 2012, p. 150). Apenas a adesão total a seus preceitos conciliaria utilidade pública e vantagem particular. Porém, para que um tal cenário se concretizasse, seria indispensável que tais princípios contassem com um forte aparato de persuasão e controle, justamente o que lhes falta. Esse estado de coisas é facilmente antevisto pela própria razão (aqui Rousseau lança o argumento dos jusnaturalistas contra eles próprios), que, diante dele, não pode senão desaconselhar a submissão aos imperativos da lei natural: "Cada um pode constatar que ela lhe seria vantajosa se todos igualmente a respeitassem, mas, vendo que ela não tem nenhuma força para obrigar os outros, seria desarrazoado ser o único a respeitá-la em detrimento do interesse próprio" (Vargas, 2008, p. 33). Como antecipamos, mesmo em se supondo "que ela seja conhecida pela razão, ela não seria aplicada por não apresentar nenhuma garantia” (Vargas, 2008, p. 32). E, isso, ainda que se considere a razão como a "soberana diretriz das ações humanas", para retomarmos uma expressão de Pufendorf (1734, Liv. II, Cap. II, § IX, p. 187). Nas palavras do próprio Rousseau, as leis naturais "são um jugo que cada um quer bem impor aos outros, mas não assumir para si” (1964a, p. 284), cujas supostas vantagens só se efetivariam

se, enquanto eu as observasse escrupulosamente em relação aos outros, estivesse certo de que todos as observariam em relação a mim. Mas que certeza podeis me dar a esse respeito? [...] Dai-me garantias contra toda empresa injusta ou não esperai que delas

6 "[Os indivíduos ignoram] que as leis não têm poder para protegê-los sem uma espada nas mãos de um homem [...] para fazer com que essas leis sejam postas em execução" (Hobbes, 1651, Parte II, Cap. XXI, p. 131). 
me abstenha. Podereis dizer-me que, renunciando aos deveres que a lei natural impõe a mim, privo-me ao mesmo tempo de seus direitos, e que minhas violências autorizarão todas aquelas que querer-se-á cometer contra mim. A isso consinto tanto mais de bom grado quanto não vejo como minha moderação poderia delas me garantir. [...] Não se trata de ensinar-me o que é a justiça; trata-se de mostrar-me qual interesse tenho em ser justo (Rousseau, 1964a, pp. 284-286).

Quer dizer, na falta de uma sanção natural (inexistente para Rousseau), as supostas leis naturais serão vãs, "elas só contribuirão para o ganho dos maus e para o ônus do justo" (Rousseau, 1964a, p. 326). Partindo dos excertos recémcitados e relacionando com habilidade os argumentos que, ao longo do segundo capítulo do "Manuscrito de Genebra", Rousseau lança contra "Droit naturel" e, por implicação, contra os principais tenentes do jusnaturalismo moderno, Spector oferece um esclarecedor panorama do que se afigura:

Rousseau mostra que, mesmo se ele [o ser humano] fosse mais racional, mais comedido
em seus desejos [...], ele não resistiria menos a se submeter às regras de sociabilidade.
Se ele quer, de fato, raciocinar, o indivíduo deverá admitir que ele só pode gozar de seus
direitos se ele aceitar seus deveres, e, portanto, que ele não gozará de absolutamente
nada na ausência de garantia exterior da obrigação. A moderação da paixão antissocial
certamente não seria recompensada; seria mesmo irracional ser moderado. A justiça
não tem nenhuma chance, assim, de impor-se de maneira espontânea, unicamente pela
força do raciocínio $(2012$, p. 151$)$.

Estamos aqui bem longe, fica claro, de uma instância coercitiva inquebrantável, qual alegava Haymann a respeito da lei natural (vide supra). Ora, não haveria sentido algum em fazer a eficácia do contrato social depender de uma baliza, ela própria, carente de força coativa. Fato atestado por David Cameron (1972) - um dos comentadores que quebra o consenso argumentativo em torno do vínculo inapelável entre contrato social e direito natural propalado por J.-P. Marcos -, que enxerga nessa ideia uma "reivindicação, no mínimo, discutível" (p. 198, nota 3).

Mas, se não se pode depender da eficácia impositivo-vinculante da lei natural, onde repousar o contrato social? De onde emana, então, seu poder coercitivo? O que impele à sua obediência? A resposta a essas indagações passa pela explicitação da novidade que o contrato rousseauniano representa face ao modelo esposado pelos expoentes do pensamento jusnaturalista. Confrontemolos, portanto. 


\section{O contrato social rousseauniano e a imanência da sanção}

$\mathrm{Na}$ forma contratualista tradicional, os diferentes componentes engajados no contrato encontram-se delimitados previamente ao ato de contratar: "as duas partes interessadas são anteriores ao contrato e distintas entre elas: por exemplo, o povo [um conjunto de indivíduos] e o príncipe [designado por aquele conjunto de indivíduos para tornar-se chefe de Estado]" (Althusser, 1967, pp. 22-23). E essa díade de contratantes, antecipadamente definida, celebra um acordo de trocas mútuas:

tem sempre lugar um contrato jurídico de troca do tipo doador-doador. Não apenas o contrato é uma troca, mas, se se quiser empregar a seu respeito a categoria de alienação, ele é uma alienação parcial: o indivíduo [que tornar-se-á súdito] cede apenas uma parte de seus direitos [àquele que tornar-se-á soberano] em troca [dentre outras coisas] de sua segurança (Althusser, 1967, p. 23; grifos no original). ${ }^{7}$

Ora, é justamente do fato de que as partes envolvidas nesse contrato de troca já se encontram definidas antes de sua celebração que decorre a necessidade de uma norma, também anterior a ele (a lei natural), que dê força vinculante ao compromisso então assumido.

Vejamos, em contrapartida, como o dispositivo contratual idealizado por Rousseau - "sem análogo nos filósofos precedentes" (Halbwachs, 1943, p. 99) - estrutura-se de modo a eludir esse imperativo de sanção prévia. A rigor, o contrato social rousseauniano não é um contrato. ${ }^{8}$ Rousseau, ele próprio, parecia ciente disso, ao reivindicar, no "Emílio", que "o pacto social é de uma natureza peculiar, própria apenas a ele" (1969, p. 840). É mesmo o que se depreende de sua cláusula única: "alienação total ${ }^{9}$ de cada associado, com todos seus direitos, a toda a comunidade" (Rousseau, 1964b, p. 360). Ao comentar os termos deste contrato, o filósofo genebrino chega a ponderar que o "povo não contrata senão consigo mesmo" (1969, p. 840), do que não devemos concluir que há somente

7 No início de seu artigo, Althusser é ainda mais minucioso em sua explicação sobre a natureza do contrato jurídico que a escola do direito natural coloca na origem do estado civil: "o contrato é uma convenção que se dá entre duas partes interessadas (que iremos chamar parte interessada no 1, ou PI. 1, e parte interessada no 2, ou PI. 2), a fim de proceder a uma troca: doador, doador. Exemplo: no contrato de submissão clássico entre o povo e o príncipe, a PI. 1 é o povo, a PI. 2 é o príncipe. A troca é feita nos seguintes termos: o povo promete obediência ao príncipe; o príncipe promete assegurar o bem do povo (acima de tudo pelo respeito às leis fundamentais)" (1967, pp. 14-15). No verbete enciclopédico sobre as fontes da autoridade política - "Autorité politique" -, Diderot fornece uma ilustração precisa desse modelo contratual.

8 Althusser (1967), em "Sur le Contrat social (les décalages)", foi um dos primeiros autores a explicitá-lo, e certamente o que mais ênfase deu a esse ponto.

9 Sobre o estatuto dessa "alienação total" - contraposta à "alienação parcial" em jogo no modelo jusnaturalista de contrato - e seu papel na constituição da comunidade soberana, cf. Althusser (1967, pp. 22-23). 
uma parte concernida no ato contratual (o que seria um total contrassenso ${ }^{10}$ ). Deve-se descortinar o "jogo de palavras” (Althusser, 1967, p. 19) ou a flutuação conceitual contida nessa afirmação: o "povo" há de ser considerado, de um lado, como conjunto de indivíduos, tomados um a um, que se reúne para celebrar o pacto; de outro, como comunidade, como eu comum sempre orientado para o interesse público e detentor da prerrogativa de legislar (cf. Rousseau, 1964b, p. 361). É nesse sentido que Althusser, ecoando Rousseau, irá dizer tratar-se de um ato pelo qual "um povo torna-se um povo" (1967, p. 19). ${ }^{11}$ Processo discernido e descrito pelo sociólogo durkheimiano, Halbwachs, em sua supraaludida introdução ao "Contrato social":

À diferença de todos os outros que antes dele falaram do contrato social, do pacto sobre o qual repousa a sociedade civil, Rousseau não pensa que, por esse contrato, os homens engajam-se uns para com os outros ou cada um para com aquele ou aqueles a quem é cedido o poder, mas, sim, para com eles mesmos sob dois aspectos: como particulares [...] e como partícipes conjuntos da sociedade política, da soberania (1943, p. 99).

O contrato que institui o político é, pois, um “ato de autoinstituição" (Bernardi, 2006, p. 202), que, em vez de erigir uma soberania que se exerce sobre o povo (soma dos membros do Estado individualmente considerados), erige o próprio povo (reunião dos participantes da comunidade política ${ }^{12}$ sob a égide da vontade geral) como soberano (cf. Bernardi, 2006, p. 202).

Esse devir-povo dos associados, efetivado somente com a conclusão do pacto social, indica-nos a particularidade do contrato rousseauniano. Ele mostra bem que a comunidade (que o soberano ao qual cada indivíduo deve alienar todos os seus direitos) não preexiste ao contrato, mas é, antes, seu fim (vide Althusser, 1967, pp. 18-19):

Em todo contrato, as duas partes interessadas existem anterior e exteriormente ao ato do contrato. No contrato social de Rousseau, só a PI. 1 obedece a essas condições. A

10 Com efeito, no mesmo momento em que reitera a nulidade dos engajamentos unilaterais (de uma pessoa consigo própria), Rousseau (1964b, p. 362) sublinha a especificidade do contrato social, no qual impõe-se a obrigação de uma parte (o indivíduo) para com o todo (o corpo soberano) ao qual ela irá pertencer.

11 A advertência de Rousseau, que motiva a formulação althusseriana, é a seguinte: "Portanto, antes de examinar o ato pelo qual um povo elege um rei, seria bom examinar o ato pelo qual um povo é um povo" (1964b, p. 359). Bem entendido, diferentemente do "pacto de submissão" ou do "pacto de governo" dos jusnaturalistas, no qual os indivíduos reunidos se dão um chefe, o pacto rousseauniano evidencia como uma soma de indivíduos transforma-se em comunidade jurídica, isto é, como uma multidão transforma-se em povo soberano.

12 Acerca da natureza dessa comunidade, eis o que diz Althusser: "O que é a comunidade? Do que ela é composta? Dos mesmos indivíduos que figuram, a título individual, na PI. 1, ou seja, no outro polo da troca. $\mathrm{Na}$ PI. 2, eles figuram não mais a título individual, mas todos 'em corpo'; portanto, sob uma outra forma, sob uma outra 'maneira de ser', justamente a forma de um 'todo', de uma 'união'. É isso a comunidade" (1967, p. 18). 
PI. 2, ao contrário, elude-as. Ela não existe anteriormente ao contrato por uma boa razão: ela própria é produto do contrato. O paradoxo do contrato social é, portanto, colocar face a face duas PIs., sendo que uma existe anterior e exteriormente ao contrato e a outra não é nem anterior nem exterior a ele [...].

De fato, a 'natureza do ato' deste contrato é tal que sua estrutura se encontra profundamente modificada em relação ao seu modelo jurídico estrito. Sob o conceito jurídico de contrato, tem lugar um contrato excepcional, de estrutural paradoxal (Althusser, 1967, pp. 15 e 18). ${ }^{13}$

Explicitamente apoiado em Althusser, Yves Vargas reitera esse caráter paradoxal do contrato rousseauniano:

para estabelecer um contrato, é preciso que os contratantes existam antes do contrato; ora, não é o caso em Rousseau, uma vez que ele diz que cada um faz um contrato com todos, um "todos" que não existe antes do contrato, pois é o contrato que cria a associação, que faz existir o todos. [...] Do ponto de vista estrutural, não se trata de um contrato (2008, p. 49).

Pois bem, o fato de a segunda parte concernida no contrato surgir somente a posteriori carrega consigo uma implicação decisiva. A forma contratual canônica, vimos, requer uma sanção prévia porque ambas as partes contratantes lhe antecedem. Mutatis mutandis, um tipo contratual em que uma das partes é forjada pelo próprio pacto só irá reclamar sanção posteriormente à sua celebração, posteriormente ao advento da segunda parte interessada, não havendo, assim, qualquer necessidade de uma lei natural anterior ao contrato para assegurar sua eficácia. ${ }^{14}$ Será, bem entendido, a própria comunidade jurídica resultante do ato contratual a responsável, ex post facto, por enforçar a obediência àquilo que fora estipulado por ele. Quer dizer, o Estado, ele mesmo, irá garantir a obediência às leis civis que os indivíduos associados prescreveram-se. $\mathrm{O}$ contrato social concebido por Rousseau repousa sobre si mesmo, ele é fonte de sua própria sanção. Uma sanção, portanto, que se impõe estritamente sob o signo da imanência, dispensando o auxílio de quaisquer poderes coercitivos exteriores - lei natural, lei divina, costumes etc. - à ordem político-jurídica engendrada pelo pacto: ${ }^{15}$

13 Dada a centralidade dessa reflexão para seu artigo, nas páginas seguintes Althusser ainda se vê às voltas com ela: "o contrato de Rousseau não corresponde a seu conceito. De fato, seu contrato social não é um contrato, mas o ato de constituição da segunda parte interessada [...], ou seja, da comunidade jurídica" (1967, pp. 20-21)

14 De nosso conhecimento, Vargas (2008, pp. 49-51) foi o primeiro a ter recorrido aos aportes althusserianos sobre a natureza do pacto fundamental no intuito de desenredar, em Rousseau, lei natural e contrato social.

15 Posição secundada por Halbwachs (1943, p. 110), que afirma não haver para Rousseau nenhuma lei fundamental ou princípio moral exterior ao pacto que vincule e obrigue aqueles que o celebram. 
a noção [rousseauniana] de soberania significa, antes de mais nada, que o político é uma ordem própria, imanente, que não tem outra medida a não ser si mesma. [...] Uma potência política não pode ser limitada senão por outra do mesmo gênero [o que se verifica, por exemplo, entre duas potências em guerra] (Bernardi, 2006, p. 197).

Resumidamente, cabe à força pública que acompanha a emergência de qualquer corpo político soberano, e só a ela, fazer valer a legislação acordada no momento do contrato por cada um de seus membros (como sendo expressão da vontade geral). A esse respeito, as palavras de Rousseau são inequívocas:

Para que o contrato social não seja um formulário vão, é preciso que, independentemente do consentimento dos particulares, o soberano tenha algumas garantias de seus engajamentos perante a causa comum. O juramento é ordinariamente a primeira dessas garantias; mas, [...] como todos modificam como quiserem - segundo suas máximas internas - a obrigação que lhes é imposta, conta-se pouco com ele nas instituições políticas, e prefere-se com razão garantias mais reais, tiradas da coisa mesma. Assim, o pacto fundamental compreende tacitamente esse compromisso, o único que pode dar força a todos os outros: aquele que recusar obedecer à vontade geral a isso será constrangido por todo o corpo (1964a, p. 292, grifos nossos).

Sem o excurso sobre o juramento, esse trecho é mantido na versão definitiva do "Contrato social" com um adendo (profundamente oximórico) que se tornou objeto de longa polêmica entre intérpretes de Rousseau: ${ }^{16}$ "aquele que recusar obedecer à vontade geral a isso será constrangido por todo o corpo; o que não significa outra coisa senão que será forçado a ser livre" (1964b, p. 364, nós grifamos). Rousseau não faz mais aqui, entretanto, do que reafirmar o poder de sanção (exclusivo) do corpo político instituído. Aquele que aquiesceu ao pacto fundamental concordou em colocar-se "sob a suprema direção da vontade geral" (Rousseau, 1964b, p. 361), o que equivale a dizer que concordou em obedecer às leis civis - expressões da vontade geral:

Assim, se eu discordo de alguma lei, enquanto expressão da vontade geral, ainda assim devo cumpri-la, e, se me recusar, serei coagido a fazê-lo, e essa coação está em princípio de acordo com minha vontade inicial que deu seu consentimento ao princípio de universalidade da qual ela proveio (Marques, 2010, p. 106). ${ }^{17}$

16 Lê-se, a propósito, Marques (2010, pp. 99 e seguintes).

17 Juízo idêntico já havia sido proferido, de forma um pouco mais lacônica, por Halbwachs: "Assim, pelo contrato social engajamo-nos tacitamente a aceitar que constranjam-nos pela força [estatal] a observar as leis" (1943, p. 111). 
Ora, nada mais natural do que uma comunidade impor o respeito às suas leis. A sentença rousseauniana causa estranhamento apenas entre aqueles que, na esteira de Hobbes (vide 1651, Parte I, Cap. XIV, pp. 79-80), equacionam a liberdade à ação totalmente desimpedida, à independência, aplicando à leitura de Rousseau um esquema conceitual que ele rejeita e, nas "Cartas escritas da montanha", desautoriza textualmente:

É inútil querer confundir independência e liberdade. Essas duas coisas são tão diferentes que até mesmo se excluem mutuamente. Quando cada um faz o que bem quer, faz-se frequentemente o que desagrada aos outros, e isso não se chama um Estado livre. A liberdade consiste menos em fazer sua vontade do que em não ser submetido à vontade de outro; ela consiste ainda em não submeter a vontade de outro à nossa. [...] Não conheço vontade verdadeiramente livre que não seja aquela à qual ninguém tem o direito de opor resistência; na liberdade comum, ninguém tem o direito de fazer aquilo que a liberdade de um outro o proíbe de fazer, e a verdadeira liberdade nunca é destrutiva em relação a si mesma. Assim, a liberdade sem a justiça é uma verdadeira contradição, pois, não importa o que se pense, tudo constrange na execução de uma vontade desordenada. Não há, pois, liberdade sem leis, nem onde alguém esteja acima das leis [...]. Um povo livre obedece, mas não serve (1964c, pp. 841-842, ênfases nossas).

Depreende-se dessa passagem, ademais, que o aparato estatal responsável por conferir sanção ao contrato que lhe deu origem desempenha um papel fundamental na preservação da liberdade dos cidadãos. Isso porque uma liberdade definida como não submissão a vontades particulares só pode ser realizada se a lei for irrestritamente observada, isto é, se a integralidade daqueles que compõem o corpo político estiver sob seu jugo exclusivo. A força pública será justamente a responsável por impingir o cumprimento generalizado das leis civis, propiciando a cada cidadão a garantia de reciprocidade cuja ausência, vimos no item anterior, dissuadia o homem do estado pré-civil de adotar os preceitos da lei natural. Invertendo a fórmula que mobilizamos acima para resumir o ceticismo de Rousseau quanto à aplicabilidade de uma suposta lei de natureza carente de poder coercitivo, podemos dizer, no concernente às leis positivas instituídas pelo contrato e amparadas pela "espada pública", que cada cidadão irá respeitá-las - quer dizer, cada um irá seguir o interesse geral - pois tem a certeza de que os outros farão o mesmo. ${ }^{18}$ Nesse novo cenário, utilidade pública e interesse individual ver-se-iam conciliados.

18 "Se Rousseau acredita ser indispensável colocar a força a serviço do direito, é para dar a cada cidadão a garantia que ele não será tolo, que [...] os outros não desobedecerão às leis. O indivíduo pode permanecer fora do pacto e renunciar às vantagens da sociedade, mas, se ele aceita suas vantagens, ele aceita, no mesmo golpe, que se o constranja a suportar suas obrigações. [...] A força a serviço do direito não se confunde com o direito do mais forte; trata-se, antes, do contrário" (Halbwachs, 1943, pp. 112-113; nós grifamos). 
Enfim, para um pensamento em que a liberdade é "a obediência à lei que se prescreveu a si mesmo" (Rousseau, 1964b, p. 365), forçar alguém a ser livre significa simplesmente forçá-lo a cumprir a lei: "Se ser livre é estar imune à interferência arbitrária de sujeitos particulares, é fácil aceitar que o sistema de coerções, ao impedir que qualquer sujeito particular se coloque acima da lei, atua verdadeiramente como garantia essencial da liberdade de cada um dos membros da sociedade" (Marques, 2010, p. 107).

\section{Referências}

ALTHUSSER, L. “Sur le Contrat social (les décalages)”. Les Cahiers Pour L'Analyse, Nr. 8 ("L'impensé de Jean-Jacques Rousseau"), Paris, pp. 5-42, 1967.

BERNARDI, B. "La fabrique des concepts: Recherche sur l'invention conceptuelle chez Rousseau". Paris: Honoré Champion, 2006.

CAMERON, D. "Rousseau, Professor Derathé and natural law". Political Studies, Vol. XX, Nr. 2, pp. 195-201, junho 1972. Disponível em http://onlinelibrary.wiley.com/ doi/10.1111/j.1467-9248.1972.tb01071.x/abstract.

DERATHÉ, R. "Rousseau e a ciência política de seu tempo". Tradução para o português de Natália Maruyama. São Paulo: Discurso Editorial/Barcarolla, 2009.

DIDEROT, D. “Autorité politique”. In: D. Diderot, J. le R. D'alembert (eds.). Encyclopédie, ou dictionnaire raisonné des sciences, des arts et des métiers. University of Chicago: ARTFL Encyclopédie Project [Online]. Disponível em http://encyclopedie. uchicago.edu/ (Acessado em 23 de abril de 2016).

GROTIUS, H. "Du droit de la guerre et de la paix". Tradução para o francês de Jean Barbeyrac. Bâsle: Emanuel Thourneisen (Edição reimpressa pela Bibliothèque National de France), 1746. Disponível em http://gallica.bnf.fr/ark:/12148/bpt6k865233.image. f2. vignettesnaviguer.

HALBWACHS, M. "Introduction, annotations et commentaires au Contrat social de Jean-Jacques Rousseau”. In: J.-J. Rousseau. Contrat social. Paris: Aubier-Montaigne, 1943.

HAYMANN, F. "La loi naturelle dans la philosophie politique de Rousseau". In: Annales de la Société Jean-Jacques Rousseau, Vol. XXX, Genève, 1943-1945. pp. 65-110.

HOBBES, Th. "Leviathan or the matter, forme, \& power of a common-wealth ecclesiasticall and civill". Londres: Andrew Crooke (Edição eletrônica preparada por Rod Ray para o McMaster University Archive of the History of Economic Thought), 1651. . "Do cidadão". Tradução para o português de Renato Janine Ribeiro. São Paulo: Martins Fontes, 2002.

HOCHART, P. "Droit naturel et simulacre”. Les Cahiers Pour L'Analyse, Paris, Nr. 8 (“L’impensé de Jean-Jacques Rousseau”), pp. 65-84, 1967.

MARCOS, J.-P. "La question de la loi naturelle selon Rousseau”. Études Jean-Jacques Rousseau, Musée Jean-Jacques Rousseau, Montmorency, Nr. 7 ("Politique de Rousseau"), pp. 161-180, 1995. 
MARQUES, J. O. de A. "Forçar-nos a ser livres? O paradoxo da liberdade no Contrato social de Jean-Jacques Rousseau". Cadernos de Ética e Filosofia Política, São Paulo, Nr. 16, pp. 99-114, 1/2010. Disponível em http://www.unicamp.br/ jmarques/pesq/ Forcar-nos_a ser_livres.pdf.

PUFENDORF, S. "Du droit de la nature et des gens ou système général de la morale, de la jurisprudence et de la politique". Tradução para o francês de Jean Barbeyrac. Amsterdam: Pierre de Coup (Edição reimpressa pela University of Toronto), 1734. Disponível em https://archive.org/details/ledroitdelanatur01pufe.

ROUSSEAU, J.-J. "Du contract social ou Essai sur la forme de la République (Première version; Manuscrit de Genève)". In: Oeuvres Complètes, Vol. III. Paris: Gallimard (Bibliothèque de la Pléiade), 1964a.

. "Du contract social ou principes du droit politique". In: Oeuvres Complètes, Vol. III. Paris: Gallimard (Bibliothèque de la Pléiade), 1964b.

. "Lettres écrites de la montagne". In: Oeuvres Complètes, Vol. III. Paris: Gallimard (Bibliothèque de la Pléiade), 1964c.

. "Emile ou de l'éducation". In: Oeuvres Complètes, Vol. IV. Paris: Gallimard (Bibliothèque de la Pléiade), 1969.

SPECTOR, C. "De Diderot à Rousseau: la double crise du droit naturel moderne". In: B. Bachofen, B. Bernardi, G. Olivo, G. (eds.). Rousseau, Du contract social, ou Essai sur la forme de la République (Manuscrit de Genève). Paris: Vrin, 2012. Disponível em http://www.celinespector.com/wp-content/uploads/2011/02/MsG-Droit-naturel.pdf. VARGAS, Y. "Rousseau et le droit naturel”. Revista Trans/form/ação, São Paulo, Nr. 31, pp. 25-52, 2008. Disponível em http://www2.marilia.unesp.br/revistas/index.php/ transformacao/article/view/967/871.

VAUGHAN, C. E. "The political writings of Jean-Jacques Rousseau, volume I". Cambridge: Cambridge University Press (Edição digitalizada pela Open Library of Liberty), 1915. Disponível em http://oll.libertyfund.org/titles/rousseau-the-politicalwritings-of-jean-jacques-rousseau-vol-1--5. 